\title{
Oncogenic activity of insulin in the development of non-small cell lung carcinoma
}

\author{
JIE JIANG $^{1 *}$, HONG-YUE REN ${ }^{2 *}$, GUO-JUN GENG ${ }^{1 *}$, YAN-JUN MI ${ }^{1}$, \\ YU LIU $^{3}$, NING LI ${ }^{1}$, SHU-YU YANG ${ }^{4}$ and DONG-YAN SHEN ${ }^{3}$ \\ ${ }^{1}$ Department of Thoracic Surgery, The First Affiliated Hospital of Xiamen University, \\ Xiamen, Fujian 361003; ${ }^{2}$ Department of Pathology, The Affiliated Southeast Hospital of \\ Xiamen University, Zhangzhou, Fujian 363000; Departments of ${ }^{3}$ Biobank and ${ }^{4}$ Xiamen Diabetes Institute, \\ The First Affiliated Hospital of Xiamen University, Xiamen, Fujian 361003, P.R. China
}

Received July 14, 2016; Accepted August 17, 2017

DOI: $10.3892 / \mathrm{ol} .2017 .7347$

\begin{abstract}
Insulin is associated with the progression of numerous different types of cancer. However, the association between insulin and non-small cell lung carcinoma (NSCLC) remains unknown. The aim of the present study was to evaluate the role of insulin in the proliferation, migration and drug resistance of NSCLC cells, and to determine whether the phosphoinositide 3-kinase/protein kinase B (PI3K/Akt) pathway was involved. NSCLC cells were treated with insulin in the absence or presence of LY294002, an inhibitor of the PI3K/Akt pathway. Following co-incubation with insulin, cell proliferation and drug resistance were measured by MTT; cell migration was examined by wound healing and Transwell assays; and the expression of cyclin A, proliferating cell nuclear antigen (PCNA), p27, matrix metalloproteinase 3 (MMP3), $\mathrm{P}-\mathrm{gp}$ and proteins involved in the PI3K/Akt pathway were assessed via western blotting. The results of the current study demonstrated that insulin enhanced the proliferation, migration and drug resistance of NSCLC cells. Correspondingly, insulin upregulated the expression of cyclin A, PCNA, MMP3, P-gp and downregulated p27 expression in NSCLC cells. Following treatment with insulin, it was demonstrated that phospho-Akt expression increased in a dose-dependent manner. However, the effects of insulin on NSCLC cells was inhibited by the
\end{abstract}

Correspondence to: Professor Shu-Yu Yang, Department of Xiamen Diabetes Institute, The First Affiliated Hospital of Xiamen University, 55 Zhenhai Road, Xiamen, Fujian 361003, P.R. China

E-mail: xmyangshuyu@163.com

Professor Dong-Yan Shen, Department of Biobank, The First Affiliated Hospital of Xiamen University, 55 Zhenhai Road, Xiamen, Fujian 361003, P.R. China

E-mail: shendongyan@163.com

${ }^{*}$ Contributed equally

Key words: insulin, non-small cell lung carcinoma, oncogenic activity, phosphoimositide 3-kinase/protein kinase B
PI3K/Akt pathway inhibitor LY294002. Therefore, the results of the current study indicate that insulin is associated with the development of NSCLC by activating the PI3K/Akt pathway. This may improve understanding of the mechanism of action of insulin in NSCLC in the future.

\section{Introduction}

Lung cancer is one of the most common types of cancer and remains the leading cause of cancer-associated mortality in the world (1). Non-small cell lung carcinoma (NSCLC) accounts for $\sim 85 \%$ of all lung cancer cases (2) and the majority of patients with NSCLC are diagnosed at an advanced stage (3). Despite improvements in the diagnosis and treatment of NSCLC, the 5-year survival rate for NSCLC remains low, at between 10 and $20 \%(4,5)$. Therefore, it is important to identify key risk factors and to design novel therapeutic strategies to prevent or treat NSCLC.

Previous studies have suggested that $\sim 20 \%$ of all types of cancer are due to obesity $(6,7)$. Obesity is strongly associated with the development of type II diabetes mellitus, which is accompanied by elevated insulin levels (8). Epidemiological studies have demonstrated that increased insulin levels are associated with an increased risk of developing cancer, including breast, pancreatic, colon and bladder cancer (9-12). Insulin acts as a powerful mitogen and has been implicated in the onset and progression of tumors (13-15). High levels of insulin accelerated the proliferation of pancreatic ductal cells and increased migration in breast cancer and colon cancer cells (13-15). However, the effect of insulin on NSCLC has not yet been evaluated.

Activation of the phosphoinositide 3-kinase/protein kinase $\mathrm{B}$ (PI3K/Akt) signaling pathway indicates poor patient prognosis and is associated with different types of cancer, including NSCLC, prostate and breast cancer (16-18). Furthermore, activation of the PI3K/Akt signaling pathway may promote tumor cell proliferation, migration and drug resistance (19). It has been demonstrated that insulin stimulates the PI3K/Akt signaling pathway to increase carcinogenesis in breast cancer and colon cancer cells (14). However, it remains unknown whether insulin is able to regulate the development of NSCLC by activating the PI3K/Akt signaling pathway. 
The results of the present study indicated that insulin enhanced the proliferation, migration and drug resistance of NSCLC cells. In addition, LY294002, a specific inhibitor of the PI3K/Akt signaling pathway, reversed the oncogenic effects of insulin on protein expression. The results of the present study may therefore improve understanding of the effect of insulin on NSCLC.

\section{Materials and methods}

Reagents. Insulin, LY294002, diamminedichloroplatinum (DDP), RNase A, propidium iodide (PI) and RIPA buffer were purchased from Sigma-Aldrich; Merck KGaA (Darmstadt, Germany). BCA Protein Assay kit and enhanced chemiluminescence (ECL) reagent were purchased from Thermo Fisher Scientific, Inc., Waltham, MA, USA. RPMI-1640, high-glucose Dulbecco 's modified Eagle's medium (DMEM) and fetal bovine serum (FBS) were purchased from Gibco; Thermo Fisher Scientific, Inc. Transwell chambers and Matrigel Invasion Chambers were purchased from BD Biosciences, Inc., Rockville, MD, USA. Antibodies against $\beta$-actin (cat. no. 3700), phospho-Akt (p-Akt, cat. no. D25E6) and Akt (cat. no. 11E7) were purchased from Cell Signaling Technologies, Inc., Danvers, MA, USA. Antibodies against insulin receptor substrate 1 (IRS1, cat. no. ab52167) and phospho-IRS1 (p-IRS1, cat. no. ab1194) were purchased from Abcam, Cambridge, UK). Antibodies against proliferating cell nuclear antigen (PCNA, cat. no. sc-25280), cyclin A (cat. no. sc-751), p27 (cat. no. sc-528), P-glycoprotein (P-gp, cat. no. sc-55510) and matrix metalloproteinase 3 (MMP3, cat. no. sc-21732) were all purchased from Santa Cruz Biotechnology, Dallas, TX, USA. Goat anti-mouse IgG (cat. no. 31430) and goat anti-rabbit IgG (cat. no. 31460) secondary antibodies conjugated to horseradish peroxidase (HRP) were purchased from Invitrogen; Thermo Fisher Scientific, Inc.

Cell culture. The human lung cancer cell lines A549, PC-9 and NCI-H1975 were provided by Dr Yan-Jun Mi (The First Affiliated Hospital of Xiamen University, Xiamen, China). Cells were maintained in RPMI-1640 medium (NCI-H1975 cells) or DMEM (A549 and PC-9 cells) supplemented with $10 \% \mathrm{FBS}$ and $100 \mathrm{U} / \mathrm{ml}$ penicillin at $37^{\circ} \mathrm{C}$ in a humidified atmosphere of $5 \% \mathrm{CO}_{2}$

Cell proliferation assay. Cell proliferation was determined using MTT, which was dissolved in dimethyl sulfoxide. Cells were suspended at a concentration of $5 \times 10^{3} /$ well, seeded into a 96 -well plate and incubated overnight at $37^{\circ} \mathrm{C}$. Following treatment with different concentration of insulin $(0,400,800,1600 \mathrm{nM}), 20 \mu \mathrm{l}$ MTT $(5 \mathrm{mg} / \mathrm{ml})$ was added to each well and the plate was incubated under the same conditions for $4 \mathrm{~h}$. Absorbance was measured at $490 \mathrm{~nm}$ using an auto microplate reader. All experiments were performed in triplicate.

Drug resistance assay. Cells were seeded into a 96-well plate at a concentration of $5 \times 10^{3} /$ well. Following treatment with $1,600 \mathrm{nM}$ insulin in the presence of various concentrations of DDP $(0,5,10,20$ and $40 \mu \mathrm{mol})$ at $37^{\circ} \mathrm{C}$ for $48 \mathrm{~h}, 20 \mu \mathrm{l} \mathrm{MTT}$ $(5 \mathrm{mg} / \mathrm{ml})$ was added to each well and the subsequent steps were performed according to the aforementioned cell proliferation assay protocol. The group treated with PBS acted as a control.

Flow cytometry. A549 cells were synchronized through treatment with serum-free high-glucose DMEM for $24 \mathrm{~h}$. Following the addition of serum-free high-glucose DMEM with or without insulin (1,600 nM) for 3 days, A549 cells were harvested, washed twice with ice cold PBS and fixed with ice cold $70 \%$ ethanol at $4^{\circ} \mathrm{C}$ overnight. Cells were washed with cold PBS and incubated with RNase A $(100 \mu \mathrm{g} / \mathrm{ml})$ at $37^{\circ} \mathrm{C}$ for $30 \mathrm{~min}$. Cells were subsequently stained with PI $(50 \mu \mathrm{g} / \mathrm{ml})$ at $4^{\circ} \mathrm{C}$ for $30 \mathrm{~min}$ and analyzed using a BD FACSCalibur Flow Cytometer (BD Biosciences, San Jose, CA, USA). The data were analyzed with the ModFit 3.3 (Verity Software House, Topsham, ME, USA) software. All experiments were performed in triplicate.

Cell migration and invasion assay. Cell migration was detected by wound healing and transwell assays, which were performed following a previously described protocol (20). A549 cells were used to investigate cell migration and invasion assay due to the characteristic of easy culture ability. For the wound healing assay, scratches were made with 10- $\mu 1$ micropipette tip. Then, serum-free high-glucose DMEM was added with or without insulin (1,600 nM). For the transwell assay, A549 cells were suspended at a concentration of $1 \times 10^{5} /$ well, seeded into the upper chamber of a 24-well plate in serum-free high-glucose DMEM with or without insulin $(1,600 \mathrm{nM})$ for $24 \mathrm{~h}$. A total of $500 \mu \mathrm{l}$ DMEM was added to the lower chamber. The cells that migrated to the lower chamber were stained with $0.05 \%$ crystal violet at room temperature for $10 \mathrm{~min}$ and counted using an inverted microscope. Cell invasion assays were performed using transwell invasion chambers with Matrigel. A549 cells were seeded at a density of $1 \times 10^{5} /$ well into the upper chamber of a 24-well plate in serum-free high-glucose DMEM with or without insulin $(1,600 \mathrm{nM})$, and incubated for $24 \mathrm{~h}$. The subsequent steps were performed according to the aforementioned transwell assay protocol. All experiments were performed in triplicate.

Western blotting. Western blotting was performed as previously described (20). Total protein was extracted using RIPA buffer and its concentration was evaluated using the BCA Protein Assay kit. Proteins were separated using 10\% SDS-PAGE and transferred onto a polyvinylidene difluoride membrane. Following blocking with 5\% milk in PBST at room temperature for $1 \mathrm{~h}$, the membrane was incubated with primary antibodies ( $\beta$-actin, 1:1,000; p-Akt, 1:1,000; Akt, 1:1,000; IRS1, 1:1,000; p-IRS1, 1:1,000; PCNA, 1:500; cyclin A, 1:500; p27, 1:500; P-gp, 1:500; MMP3, 1:500) at $4^{\circ} \mathrm{C}$ overnight followed by incubation with the appropriate HRP-conjugated secondary antibody $(1: 10,000)$ at room temperature for $1 \mathrm{~h}$. The signal was subsequently visualized using an ECL reporter system (Thermo Fisher Scientific, Inc.) followed by exposure to X-ray film. All experiments were performed in triplicate.

Statistical analysis. Data are presented as the mean \pm standard error of the mean. Unpaired Student's t test or one-way 
A
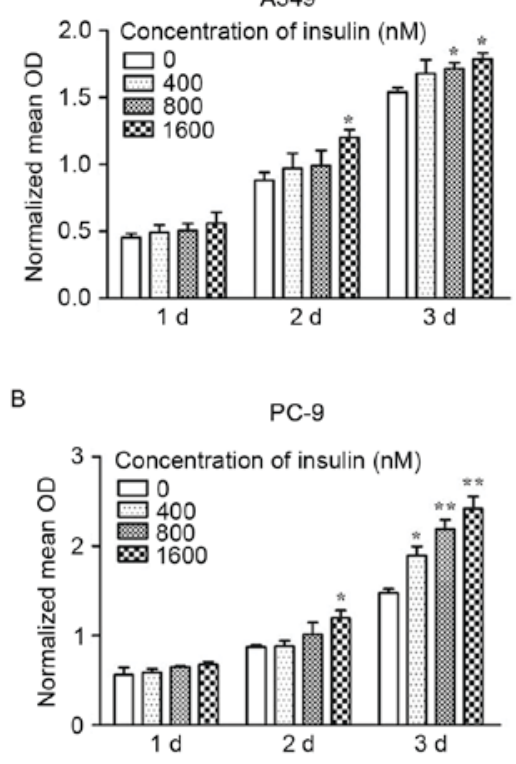

C

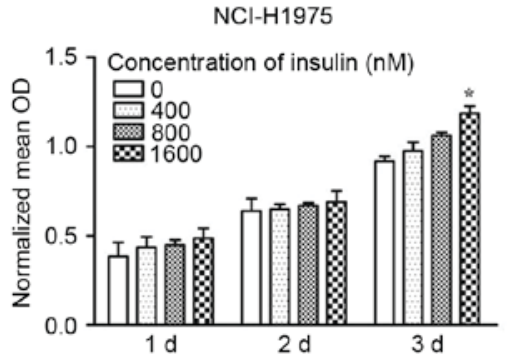

D
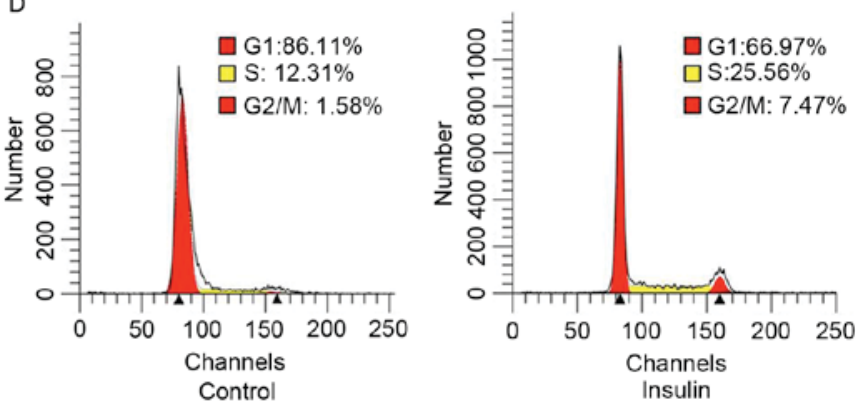

E

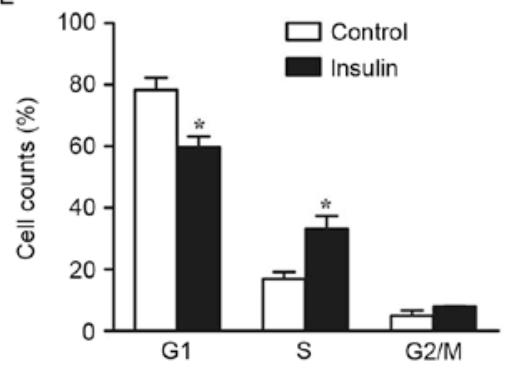

F

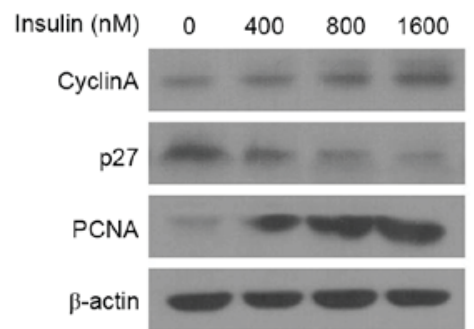

Figure 1. The proliferation of NSCLC cells following treatment with insulin. The proliferation of (A) A549, (B) PC-9 and (C) NCI-H1975 cells was measured using an MTT assay. ${ }^{*} \mathrm{P}<0.05$ and ${ }^{* *} \mathrm{P}<0.01$ vs. $0 \mathrm{nM}$ insulin. (D and E) A549 cells were treated with 1,600 nM insulin for 3 days and subsequently analyzed by flow cytometry. ${ }^{*} \mathrm{P}<0.05$ vs. the control. (F) Cyclin A, p27 and PCNA expression were assessed in A549 cells by western blotting following treatment with 400,800 and 1,600 nM insulin for 3 days. Data are presented as the mean \pm standard error of the mean. ${ }^{*} \mathrm{P}<0.05,{ }^{* *} \mathrm{P}<0.01 . \mathrm{PCNA}$, proliferating cell nuclear antigen; NSCLC, non-small cell lung cancer; d, days; OD, optical density.

A

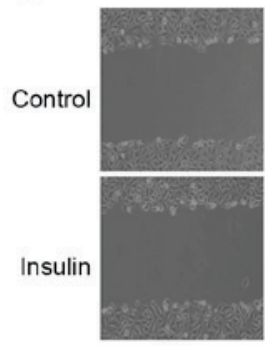

$0 \mathrm{~d}$

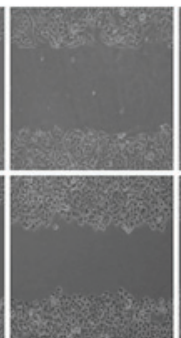

$1 \mathrm{~d}$

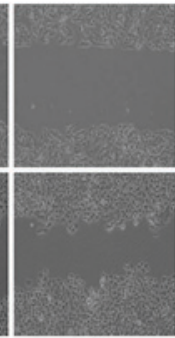

$3 d$

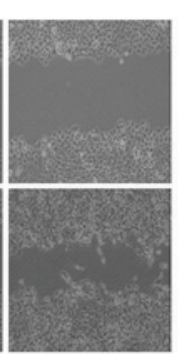

$5 d$
B

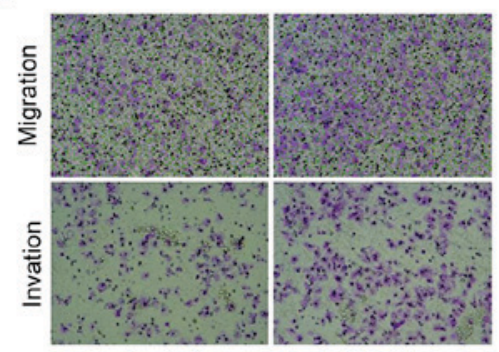

Control

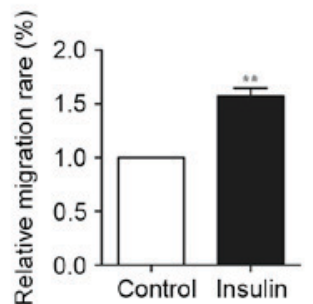

Insulin

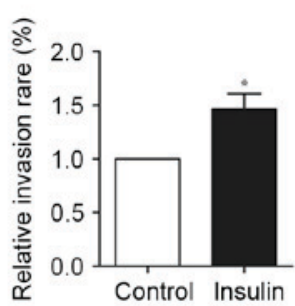

Figure 2. The migration of NSCLC cells following treatment with insulin. (A) The migration of A549 cells at $0,1,3$ and 5 days was measured by a wound-healing assay following treatment with insulin. Magnification, $x 400$. (B) The migration of A549 cells was measured by a Transwell assay following treatment with $1,600 \mathrm{nM}$ insulin for 3 days. The migration rate was calculated and quantified. Data are presented as the mean \pm standard error of the mean. ${ }^{*} \mathrm{P}<0.05$ and ${ }^{* *} \mathrm{P}<0.01$ vs. control. Magnification, $\mathrm{x} 400$. (C) The expression of MMP3 was assessed by western blotting following treatment with $1,600 \mathrm{nM}$ insulin for 3 days. MMP3, matrix metalloproteinase 3. 
analysis of variance were used for comparison of two or more datasets, respectively. Multiple comparison between the groups was performed using Student-Newman-Keuls method. $\mathrm{P}<0.05$ was considered to indicate a statistically significant difference. The data were analyzed with SPSS version 16.0 statistical software package (SPSS Inc., Chicago, IL, USA). All groups contained three replicates and all experiments were repeated three times.

\section{Results}

Insulin promotes the proliferation of NSCLC cells. An MTT assay was performed to determine the role of insulin in the proliferation of NSCLC cells. The proliferation of A549, PC-9 and NCI-H1975 cells were enhanced by insulin in a dose- and time-dependent manner (Fig. 1A-C; $0 \mathrm{nM}$ insulin acted as a control; ${ }^{*} \mathrm{P}<0.05$ vs. $0 \mathrm{nM}$ insulin at 2 or $3 \mathrm{~d}$ in A549, PC-9 or NCI-H1975 cells; ${ }^{* *} \mathrm{P}<0.01$ vs. $0 \mathrm{nM}$ insulin at $3 \mathrm{~d}$ in PC-9 cells). The enhancing effect of insulin on the proliferation of the aforementioned cells, were more obvious by day 3 . In addition, the results of flow cytometry demonstrated that insulin significantly decreased the proportion of cells in the G1 phase $(\mathrm{P}<0.05)$ and significantly increased the proportion of cells in the S-phase compared with control $(\mathrm{P}<0.05$; Fig. 1D and E). Western blotting was performed to measure the expression of cell cycle and growth-related proteins in A549 cells. The expression of cyclin A and PCNA were increased and of p27 protein expression was decreased in a dose-dependent manner following treatment with insulin (Fig. 1F). These results indicate that insulin promotes the proliferation of the NSCLC cells.

Insulin promotes the migration and invasion of NSCLC cells. Subsequently, the effect of insulin on NSCLC migration and invasion was detected by wound healing and Transwell assays. The ability of migration and invasion were markedly elevated by insulin in A549 cells (Fig. 2A and B). Furthermore, the number of migrating and invading A549 cells were significantly increased following treatment with insulin compared with untreated control cells (Fig. 2B; $\mathrm{P}<0.05$ ). In addition, insulin enhanced the expression of MMP 3 in a dose-dependent manner in A549 cells (Fig. 2C). Taken together, these results suggest that insulin may promote the migration and invasion of NSCLC cells by regulating MMP3 expression.

Insulin increases the resistance of NSCLC cells to DDP. To investigate the effect of insulin on drug resistance, A549 and PC-9 cells were treated with different concentrations of DDP $(0,5,10,20$ and $40 \mu \mathrm{mol})$ in the absence or presence of insulin. The sensitivity of A549 and PC-9 cells to DDP was significantly reduced by insulin (Fig. 3A and B; $\mathrm{P}<0.05$ ). Furthermore, the expression of P-gp in A549 cells was increased by insulin in a dose-dependent manner (Fig. 3C), indicating that insulin may reduce the sensitivity of NSCLC cells to DDP by upregulating P-gp expression.

Insulin exhibits oncogenic activity via the PI3K/Akt signaling pathway. To further explore the mechanism of insulin on cell proliferation, migration and drug sensitivity, the effect of insulin on the IRS and PI3K/Akt signaling

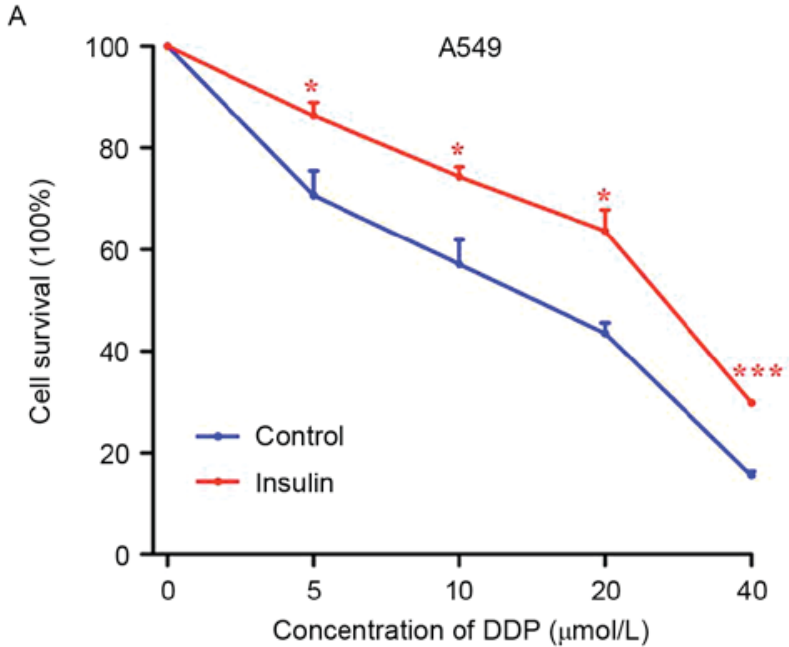

B

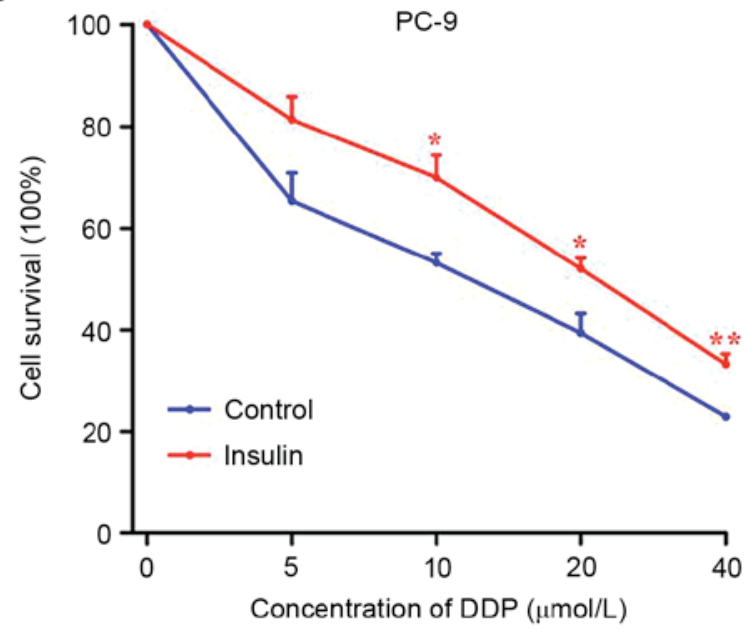

C

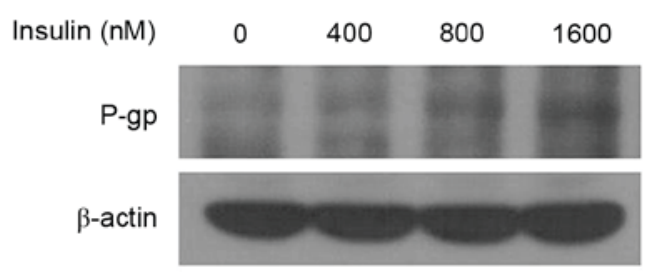

Figure 3. The susceptibility of NSCLC cells to drug treatment following treatment with insulin. Following treatment with different concentrations of $\operatorname{DDP}(0,5,10,20$ and $40 \mu \mathrm{mol})$ and/or 1,600 $\mathrm{nM}$ insulin for $48 \mathrm{~h}$, the susceptibility of (A) A549 and (B) PC-9 cells to DDP was measured by MTT. Results are presented as the mean \pm standard error of the mean. ${ }^{*} \mathrm{P}<0.05,{ }^{* * *} \mathrm{P}<0.01$ and ${ }^{* * * *} \mathrm{P}<0.001$ vs. $0 \mu \mathrm{mol}$ DDP. (C) The expression of P-gp was assessed by western blotting in A549 cells following treatment with insulin for 3 days. DDP, diamminedichloroplatinum; P-gp, P-glycoprotein.

pathway in NSCLC, which has been investigated in other types of cancer $(14,21)$, was determined by western blot analysis. The results demonstrated that insulin increased p-Akt and p-IRS1 expression in a dose-dependent manner (Fig. 4A). Furthermore, following the addition of LY294002, a PI3K/Akt inhibitor, the expression of p-Akt and p-IRS1 in A549 cells was reduced compared with cells treated with insulin alone and was similar to that of untreated control cells (Fig. 4B). Correspondingly, LY294002 also reversed the effects of insulin on the expression of cyclin A, p27, PCNA, 
A

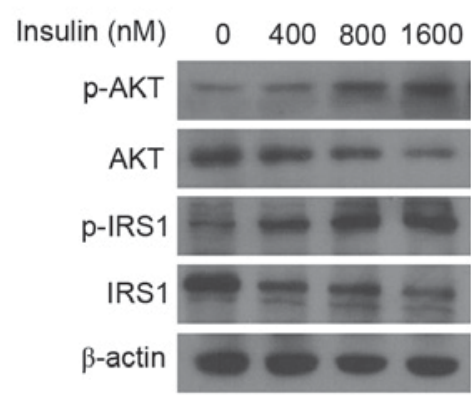

B

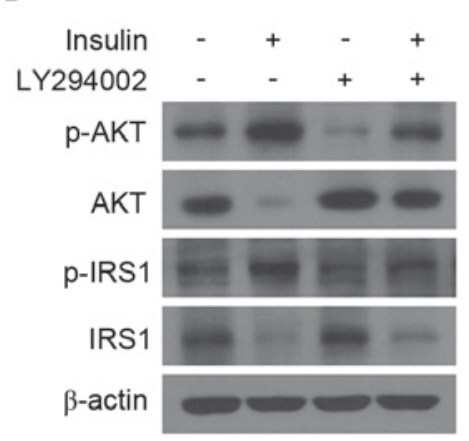

C

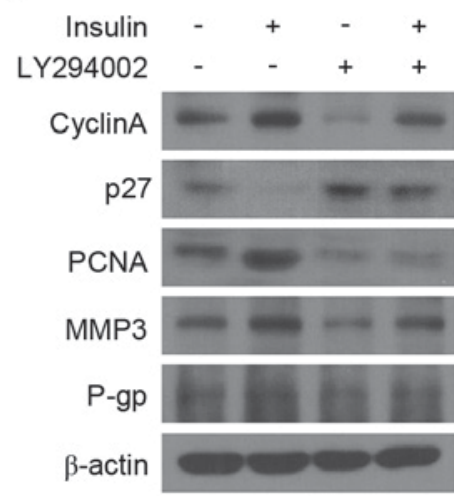

Figure 4. Insulin regulates the PI3K/Akt signaling pathway. (A) Expression of p-Akt, Akt, p-IRS1 and IRS1 were assessed by western blotting in A549 cells following treatment with $0,400,800$ and 1,600 $\mathrm{nM}$ insulin for 3 days. (B and C) Western blot analysis of A549 cells exposed to 1,600 $\mathrm{nM}$ insulin and/or $1 \mu \mathrm{M}$ LY294002 for 3 days. PI3K, phosphoinositide 3-kinase; Akt, protein kinase B; Akt, protein kinase B; p-, phosphorylated; IRS1, insulin receptor substrate 1; PCNA, proliferating cell nuclear antigen; MMP-3, matrix metalloproteinase 3; P-gp, P-glycoprotein.

MMP3 and P-gp in A549 cells (Fig. 4C). These results indicate that the PI3K/Akt signaling pathway may be involved in the oncogenic activity of insulin in NSCLC.

\section{Discussion}

The role of insulin in the pathogenesis of cancer was first reported in the 1970's (22). Insulin acts as a growth factor and may stimulate neoplastic development (23). In lung cancer, intracellular insulin activity is an important factor affecting the progression of low-grade human lung adenocarcinomas (24). Furthermore, inhaled insulin is associated with an increased incidence of lung cancer among former smokers (25).

The results of the present study revealed that insulin exhibits oncogenic activity during the development of NSCLC. Insulin markedly increased the proliferation and migration of NSCLC cells and significantly decreased the sensitivity of NSCLC cells to DDP. Cell cycle analysis demonstrated that insulin decreased the proportion of cells in the G1 phase and increased the proportion of cells in the S-phase. In addition, it was demonstrated that insulin upregulated cyclin A and PCNA expression and downregulated p27 expression in a dose-dependent manner. Furthermore, the expression of MMP3 was markedly increased following incubation with insulin in A549 cells. Lastly, insulin enhanced the expression of P-gp in a dose-dependent manner in A549 cells.

The oncogenic activity of insulin has been reported in other types of cancer tissues. Previous studies have demonstrated that insulin may contribute to the proliferation and survival of different types of cancer, including gastric, colon, pancreatic, breast and bladder cancer $(14,15,21,26)$. It has also been demonstrated that insulin potentiates the ability of lysophosphatidic acid to stimulate cell cycle progression and DNA synthesis in MCF-7 breast cancer cells. The potentiating effect of insulin appears to increase the expression level of cyclin $\mathrm{E}$ and decrease the expression level of the cyclin-dependent kinase inhibitor $\mathrm{p} 27^{\mathrm{Kip} 1}$ (27). Insulin enhances the sensitivity of gastric cancer cells to 5-fluorouracil and stimulates the migration of breast cancer cells $(14,15)$. Insulin is also able to accelerate the metabolic capacities of cancer cells by performing dual regulation of the glycolytic enzyme pyruvate kinase M2 (28).

Insulin binds to the insulin receptor and causes phosphorylation of insulin receptor (InsR) substrate proteins, followed by activation of downstream molecules including PI3K/Akt and MAPK. The activated PI3K/Akt signaling pathway is involved in various oncogenic functions, including the induction of cell proliferation, migration and drug resistance (19). Previous studies have demonstrated that insulin promotes the proliferation of pancreatic, bladder, breast and colon cancer cells via the PI3K/Akt signaling pathway $(13,14,21)$. In NSCLC, overexpression of InsR predicts poor patient survival (29). IRS1 is an adaptor protein for insulin signaling and it has been suggested that IRS1 loss occurs early on in the pathogenesis of NSCLC (30). In the present study, it was demonstrated that insulin enhanced p-Akt and p-IRS1 expression in a dose-dependent manner. Furthermore, inhibition of PI3K/Akt activation by LY294002 significantly reversed the insulin-induced increases in p-Akt, p-IRS1, cyclin A, PCNA, MMP3 and P-gp expression. At the same time, levels of Akt, IRS1 and p27 expression, which were decreased by insulin, were increased following treatment with LY294002. These results suggest that the PI3K/Akt signaling pathway is crucial for the effect of insulin on NSCLC.

In conclusion, the current study demonstrated that insulin is an oncogenic factor in the development of NSCLC that may work by activating the PI3K/Akt signaling pathway. Future studies should investigate how to counteract the oncogenic activity of insulin on NSCLC.

\section{Acknowledgements}

The current study was supported by the National Natural Science Foundation of China (grant no. 81572394), the Joint Research of Critical Diseases Foundation, Xiamen Science and Technology Bureau, China (grant no. 3502Z20159013), the Natural Science Foundation of Zhangzhou, Fujian, China (grant no. ZZ2017J36) and the Youth Nursery Foundation of the Affiliated Southeast Hospital of Xiamen University, Zhangzhou, Fujian, China (grant no. 16Y019). 


\section{References}

1. Siegel RL, Miller KD and Jemal A: Cancer statistics, 2015. CA Cancer J Clin 65: 5-29, 2015.

2. Herbst RS, Heymach JV and Lippman SM: Lung cancer. N Eng J Med 359: 1367-1380, 2008

3. Cappuzzo F, Ciuleanu T, Stelmakh L, Cicenas S, Szczésna A, Juhász E, Esteban E, Molinier O, Brugger W, Melezinek I, et al: Erlotinib as maintenance treatment in advanced non-small-cel lung cancer: A multicentre, randomised, placebo-controlled phase 3 study. Lancet Oncol 11: 521-529, 2010.

4. Spiro SG and Silvestri GA: One hundred years of lung cancer. Am J Res Crit Care Med 172: 523-529, 2005

5. van Zandwijk N and Fong KM: Update in lung cancer: Prologue to a modern review series. Respirology 20: 183-184, 2015.

6. Wolin KY, Carson K and Colditz GA: Obesity and cancer. Oncologist 15: 556-565, 2010.

7. Renehan AG, Tyson M, Egger M, Heller RF and Zwahlen M: Body-mass index and incidence of cancer: A systematic review and meta-analysis of prospective observational studies. Lancet 371: 569-578, 2008 .

8. Mehran AE, Templeman NM, Brigidi GS, Lim GE, Chu KY, Hu X, Botezelli JD, Asadi A, Hoffman BG, Kieffer TJ, et al: Hyperinsulinemia drives diet-induced obesity independently of brain insulin production. Cell Metab 16: 723-737, 2012

9. Tseng $\mathrm{CH}$ : Use of insulin and mortality from breast cancer among taiwanese women with diabetes. J Diabetes Res 2015: $678756,2015$.

10. Tseng CH: Diabetes, insulin use, smoking, and pancreatic cancer mortality in Taiwan. Acta Diabetol 50: 879-886, 2013.

11. Wang L, Cai S, Teng Z, Zhao X, Chen X and Bai X: Insulin therapy contributes to the increased risk of colorectal cancer in diabetes patients: A meta-analysis. Diagn Pathol 8: 180, 2013.

12. Tseng $\mathrm{CH}$ : Insulin use and smoking jointly increase the risk of bladder cancer mortality in patients with type 2 diabetes. Clin Genitourin Cancer 11: 508-514, 2013.

13. Chan MT,Lim GE, Skovsø S, Yang YH, Albrecht T, Alejandro EU, Hoesli CA, Piret JM, Warnock GL and Johnson JD: Effects of insulin on human pancreatic cancer progression modeled in vitro. BMC Cancer 14: 814, 2014.

14. Tomas NM, Masur K, Piecha JC, Niggemann B and Zänker KS: Akt and phospholipase Cgamma are involved in the regulation of growth and migration of MDA-MB-468 breast cancer and SW480 colon cancer cells when cultured with diabetogenic levels of glucose and insulin. BMC Res Notes 5: 214, 2012.

15. Wei Z, Liang L, Junsong L, Rui C, Shuai C, Guanglin Q, Shicai H, Zexing W, Jin W, Xiangming $C$ and Shufeng W: The impact of insulin on chemotherapeutic sensitivity to 5-fluorouracil in gastric cancer cell lines SGC7901, MKN45 and MKN28. J Exp Clin Cancer Res 34: 64, 2015.
16. Zhang C, Lan T, Hou J, Li J, Fang R, Yang Z, Zhang M, Liu J and Liu B: NOX4 promotes non-small cell lung cancer cell proliferation and metastasis through positive feedback regulation of PI3K/Akt signaling. Oncotarget 5: 4392-4405, 2014.

17. Sarker D, Reid AH, Yap TA and de Bono JS: Targeting the PI3K/AKT pathway for the treatment of prostate cancer. Clin Cancer Res 15: 4799-4805, 2009.

18. Safdari Y, Khalili M, Ebrahimzadeh MA, Yazdani Y and Farajnia S: Natural inhibitors of PI3K/AKT signaling in breast cancer: Emphasis on newly-discovered molecular mechanisms of action. Pharmacol Res 93: 1-10, 2015.

19. Martini M, De Santis MC, Braccini L, Gulluni F and Hirsch E: PI3K/AKT signaling pathway and cancer: An updated review. Ann Med 46: 372-383, 2014.

20. Huang GL, Luo Q, Rui G, Zhang W, Zhang QY, Chen QX and Shen DY: Oncogenic activity of retinoic acid receptor $\gamma$ is exhibited through activation of the $\mathrm{Akt} / \mathrm{NF}-\kappa \mathrm{B}$ and $\mathrm{Wnt} / \beta$-catenin pathways in cholangiocarcinoma. Mol Cell Biol 33: 3416-3425, 2013.

21. Liu S, Li Y, Lin T, Fan X, Liang Y and Heemann U: High dose human insulin and insulin glargine promote T24 bladder cancer cell proliferation via PI3K-independent activation of Akt. Diabetes Res Clin Pract 91: 177-182, 2011.

22. Kessler II: Cancer and diabetes mellitus. A review of the literature. J Chronic Dis 23: 579-600, 1971.

23. Home P: Insulin therapy and cancer. Diabetes Care 36 (Suppl 2): S240-S244, 2013.

24. Mattarocci S, Abbruzzese C, Mileo AM, Visca P, Antoniani B, Alessandrini G, Facciolo F, Felsani A, Radulescu RT and Paggi MG: Intracellular presence of insulin and its phosphorylated receptor in non-small cell lung cancer. J Cell Physiol 221: 766-770, 2009.

25. Kling J: Inhaled insulin's last gasp? Nat Biotechnol 26: 479-480, 2008.

26. White PB, True EM, Ziegler KM, Wang SS, Swartz-Basile DA, Pitt HA and Zyromski NJ: Insulin, leptin, and tumoral adipocytes promote murine pancreatic cancer growth. J Gastrointest Surg 14: 1888-1894, 2010.

27. Chappell J,Leitner JW, Solomon S, Golovchenko I, Goalstone ML and Draznin B: Effect of insulin on cell cycle progression in MCF-7 breast cancer cells. Direct and potentiating influence. J Biol Chem 276: 38023-38028, 2001.

28. Iqbal MA, Siddiqui FA, Gupta V, Chattopadhyay S, Gopinath P, Kumar B, Manvati S, Chaman N and Bamezai RN: Insulin enhances metabolic capacities of cancer cells by dual regulation of glycolytic enzyme pyruvate kinase M2. Mol Cancer 12: 72, 2013.

29. Kim JS, Kim ES, Liu D, Lee JJ, Solis L, Behrens C, Lippman SM, Hong WK, Wistuba II and Lee HY: Prognostic impact of insulin receptor expression on survival of patients with nonsmall cell lung cancer. Cancer 118: 2454-2465, 2012.

30. Han CH, Cho JY, Moon JT, Kim HJ, Kim SK, Shin DH, Chang J, Ahn CM, Kim SK and Chang YS: Clinical significance of insulin receptor substrate-I down-regulation in non-small cell lung cancer. Oncol Rep 16: 1205-1210, 2006. 